\title{
Influence of environmental enrichment on the behavior and physiology of mice infected by Trypanosoma cruzi
}

\author{
Déborah Maria Moreira da Silva ${ }^{[1]}$, Laila Pinheiro ${ }^{[1]}$, Cristiano Schetini Azevedo ${ }^{[1],[2],}$ \\ Guilherme de Paula Costa ${ }^{[3]}$ and André Talvani ${ }^{[2],[3],[4],[5]}$
}

[1]. Departamento de Biodiversidade, Evolução e Meio Ambiente, Campus Morro do Cruzeiro, Universidade Federal de Ouro Preto, Ouro Preto, MG, Brasil. [2]. Programa de Pós-Graduação em Biomas Tropicais, Campus Morro do Cruzeiro, Universidade Federal de Ouro Preto, Ouro Preto, MG, Brasil. [3]. Programa de Pós-Graduação em Ciências Biológicas, Campus Morro do Cruzeiro, Universidade Federal de Ouro Preto, Ouro Preto, MG, Brasil. [4]. Departamento de Ciências Biológicas, Campus Morro do Cruzeiro, Universidade Federal de Ouro Preto, Ouro Preto, MG, Brasil.

[5]. Programa de Pós-Graduação em Saúde e Nutrição, Campus Morro do Cruzeiro, Universidade Federal de Ouro Preto, Ouro Preto, MG, Brasil.

\begin{abstract}
Introduction: Enriched environments normally increase behavioral repertoires and diminish the expression of abnormal behaviors and stress-related physiological problems in animals. Although it has been shown that experimental animals infected with microorganisms can modify their behaviors and physiology, few studies have evaluated how environmental enrichment affects these parameters. This study aimed to evaluate the effects of environmental enrichment on the behavior and physiology of confined mice infected with Trypanosoma cruzi. Methods: The behaviors of 20 T. cruzi-infected mice and 20 non-infected mice were recorded during three treatments: baseline, enrichment, and post-enrichment. Behavioral data were collected using scan sampling with instantaneous recording of behavior every 30s, totaling 360h. Plasma TNF, CCL2, and IL-10 levels and parasitemia were also evaluated in infected enriched/non-enriched mice. Behavioral data were evaluated by Friedman's test and physiological data by one-way ANOVA and area under the curve (AUC) analysis. Results: Results showed that environmental enrichment significantly increased exploratory behaviors and diminished inactivity. The use of environmental enrichment did not diminish circulating levels of TNF and IL-10 but diminished circulating levels of CCL2 and parasitemia. Conclusions: Positive behavioral and physiological effects of environmental enrichment were observed in mice living in enriched cages. Thus, environmental enrichment improved the welfare of these animals.
\end{abstract}

Keywords: Chagas disease. Inflammation. Laboratory animals. Welfare.

\section{INTRODUCTION}

Stress can be defined as the biological response elicited when an individual perceives a threat to its homeostasis ${ }^{1}$. Chronic stress provoked by poor captive environments should be avoided, as it can change animal behavior. Specifically, animals may express more stereotypical abnormal behaviors (e.g. repetitive behaviors that have no apparent function) ${ }^{2}$. Moreover, chronic stress may diminish animals' immune responses, which is associated with the development of pathologies that affect not only physical ${ }^{3}$ but also emotional status (e.g., increased anxiety and fear) ${ }^{4}$. Since stress can influence the immune system, as well as the physiology and behavior of animals, results originating from studies with animals housed under such conditions can be biased and conclusions wrongly interpreted ${ }^{5-7}$.

Corresponding author: Dr. Cristiano Schetini de Azevedo.

e-mail: cristianoroxette@yahoo.com

Received 3 February 2017

Accepted 18 May 2017
One approach for avoiding, decreasing, or eliminating stress-related problems when researching captive animals is environmental enrichment ${ }^{8}$. Environmental enrichment is a method that involves the introduction of different items into enclosures to stimulate physical and psychological activities that improve animal welfare ${ }^{9}$. In other words, enrichment transforms a monotonous environment into a dynamic, complex, and unpredictable one, resulting in improvements in animal health ${ }^{10}$.

Experimental animals used in studies involving infection with pathogenic organisms can exhibit modified behavior in the presence of these infective agents ${ }^{11}$. If these animals are captive, they can also suffer from a lack of stimuli and the high predictability of their environment ${ }^{12,13}$. The synergistic effects of parasitism and living in a non-enriched captive environment may rapidly diminish the welfare of the animals ${ }^{14}$, increasing the morbidity and mortality rates of the experimentally infected animals ${ }^{15}$.

Trypanosoma cruzi is a flagellated protozoan and the causative agent of Chagas disease in humans. It is largely used in experimental infections to study the inflammatory response and chemotherapy. After invasion of mammalian 
hosts, this parasite disseminates through the blood system, promoting systemic and local activation of the immune response and provoking pathologies mainly in the heart and central nervous system ${ }^{16-19}$. Experimental mice infected with T. cruzi normally exhibit diminished locomotive-explorative behaviors, showing a tendency to run in a circular pattern and displaying a humpback walk ${ }^{11}$. In this initial phase of infection, the antigenic molecule of $T$. cruzi promotes the activation and release of inflammatory mediators and oxygen and/or nitrogen intermediary radical ${ }^{20,21}$. In particular, IFN- $\gamma$ (gamma interferon) released by T lymphocyte and NK (natural killer) cells is the main cytokine responsible for controlling parasitism during the acute phase and is pivotal in intensifying the activation of phagocyte cells and other immune cells. Meanwhile, interleukin-10 (IL-10) regulates the host immune response $^{22,23}$. Of similar importance, chemokines are known for their capacity to induce leukocyte migration and activation of immune system cells, driving these cells to parasite infection sites $^{24}$. The chemokines CCL2 [chemokine (C-C motif) ligand 2] (MCP-1 - monocyte chemoattractant protein-1) and CCL5 [chemokine (C-C motify) ligand 5] (RANTES - Regulated on Activation Normal $\mathrm{T}$ cell Expressed and Secreted)) are directly linked to lymphocyte migration and control of parasite replication, respectively ${ }^{25}$. Similarly, the lack of CCR5 (C-C chemokine receptor type 5) eliminates the ability of lymphocytes to migrate to the infection site and control parasite replication ${ }^{26}$. Thus, the balance between cytokine and chemokine production during this initial phase might determinate the intensity and severity of pathogenesis ${ }^{27,28}$, affecting the behavior and survival of these animals.

Since environmental enrichment enhances animal welfare, we hypothesize that enriched environment-reared animals will display more locomotive-explorative behaviors and fewer abnormal behaviors compared to animals reared in conventional cages. We also speculate that modulation of the immune response through reductions in TNF (Tumor Necrosis Factor), CCL2, and IL-10 will allow enriched environment-reared animals to better manage $T$. cruzi infection ${ }^{29}$. Thus, the aim of this study was to evaluate whether different physical environmental enrichment items affected the behavioral and immune responses of mice infected with $T$. cruzi.

\section{METHODS}

\section{Animals and maintenance}

Forty healthy male C57BL/6 mice aged 9-10 weeks and weighing 16-18g from the Center of Animal Science of the Federal University of Ouro Preto were used in this study.

\section{Ethical considerations}

The study was approved by the Animal Ethics Committee of the Federal University of Ouro Preto under license number 2012-60.

Mice were kept in standard autoclavable polypropylene boxes $\left(30.3 \times 19.3 \times 12.6 \mathrm{~cm}\right.$; Beira-Mar $\left.{ }^{\circledR}\right)$ with a stainless steel lid, arranged on conventional shelves, placed in a room with a controlled temperature $\left(22^{\circ} \mathrm{C}\right)$, and submitted to a 12 light $/ 12$ dark cycle (white light on from 07:00 to 19:00; acclimation period: 4 weeks). Food pellets (Nuvilab CR1®) and a bottle of filtered water were provided ad libitum. Autoclaved sawdust (Oeste ${ }^{\circledR}$ ) was used as bedding and changed twice a week. Five mice were housed together in each box. All boxes were autoclaved before use.

Mice were infected with 5,000 blood trypomastigotes of the VL-10 (Virgem da Lapa) T. cruzi strain, which belongs to the TcII discrete typing unit (DTU) ${ }^{30}$ and presents cardiac tropism and slight fibrosing inflammation in C57BL/6 $\mathrm{mice}^{31}$. Blood was diluted in $0.9 \%$ saline solution to adjust the concentration, and it was injected into mice intraperitoneally. Infected and noninfected animals were exposed to either standard or enriched housing environment ( $\mathrm{n}=10$ animals in each group). After experiments, mice were euthanized in $\mathrm{CO}_{2}$ chamber $(10 \mathrm{~L} / \mathrm{min}$ of $\left.\mathrm{CO}_{2}\right)^{32}$, and hearts were collected and weighed.

\section{Experimental protocol}

Three structural enrichment items were used in this study: PVC (polyvinyl chloride) pipes, egg boxes, and straw nests. The PVC pipe was cleaned every week with $70 \%$ alcohol and reused whenever needed. Straw nests and egg boxes were autoclaved and exchanged twice a week. The order of items for testing was defined following the Latin square design, and all items were provided separately.

The study was divided into three treatments: 1) baseline, in which data were collected before the introduction of the environmental enrichment items; 2) enrichment, in which data were collected when the enrichment items were offered; 3) post-enrichment, in which data were collected after the removal of the enrichment items when the conditions returned to those of baseline treatment. Thirty hours of behavioral data distributed over six weeks were collected for each treatment (10h for each enrichment item during enrichment treatment). Data were collected from Monday to Friday, with 1-week intervals between treatments.

Behavioral data were collected using scan sampling with instantaneous recording of behaviors every $30 \mathrm{~s}^{33}$. Each behavioral sampling lasted $30 \mathrm{~min}$, totaling $360 \mathrm{~h}$ of behavioral data; samplings occurred from 12:00 to 12:30 and from 16:00 to $16: 30$, since mice were most active during these hours based on $20 \mathrm{~h}$ of preliminary observations (Figure 1A). All data were collected with the researcher $1 \mathrm{~m}$ from the boxes to avoid researcher interference in mouse behavior.

\section{Ethogram}

An ethogram for mice was built based on $20 \mathrm{~h}$ of preliminary observation using an ad libitum recording method ${ }^{33}$ and consultation with the scientific literature ${ }^{34}$ (Table 1).

\section{Parasitemia}

Comparisons between the number of circulating parasites in blood samples of enriched and non-enriched mice were performed. For this, blood was collected from another 20 male C57BL/6 mice aged 9-10 weeks and weighing 16-18g from the Center of Animal Science of the Federal University of 
(A)

Trypanosoma cruzi

infection
June $21 \mathrm{st}$

2013

Dav $1 \quad 1 \quad 3$

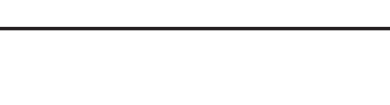

(B)

\section{Baseline \\ Interval between treatments}

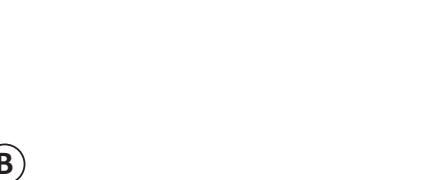

Trypanosoma cruzi infection

December 23rd, 2013

2013

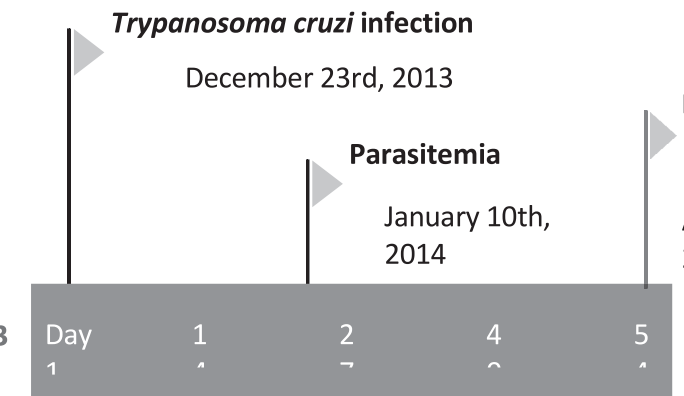

\section{End of experiment}

April 4th, 2014

2014
Blood sample:

cytokine/chemokine

November 16th

End of experiments

November

16th

2013

\section{Enrichment}

January 06th, 2014 - February

14th, 2014

FIGURE 1 - Graphic timeline for the recording of behavioral and physiological data of C57BL/6 mice. A. Timeline for behavioral and physiological data recording. B. Timeline for parasitemia data recording.

\section{TABLE 1}

Ethogram for the behaviors recorded for C57BL/6 mice.

\begin{tabular}{|c|c|c|}
\hline Behavior & Acronym & Description \\
\hline Grooming & GRO & Mouse cleans its own fur. \\
\hline Exploration & EXP & Mouse explores the box, sniffing and walking, without exploring the roof of the box. \\
\hline Roof exploration & EXR & Mouse explores the roof of the box, sniffing and hanging on lid. \\
\hline Negative social interaction & IS- & Mouse intimidates, attacks, or bites another mouse, mutilating it. \\
\hline Abnormal behaviors & $\mathrm{ABN}$ & $\begin{array}{c}\text { Mouse bites the lid or jumps in a repetitive or stereotypical way or exhibits negative allogrooming of } \\
\text { another mouse (when the grooming is so intense and repetitive that the fur of the groomed mouse is } \\
\text { plucked). }\end{array}$ \\
\hline Not visible & NV & Mouse not visible. \\
\hline
\end{tabular}

AG: allogrooming, GRO: grooming, EXP: exploration; EXR: roof exploration; IN: inactivity; IS-: negative social interaction; ABN: abnormal behaviors; NV: not visible. 
Ouro Preto. These mice were maintained under the same conditions as the other animals (acclimation period: 4 weeks). New animals were required since the peak of parasitemia occurred 27 days after infection; in the original group, this peak occurred before the enrichment treatment, preventing assessment of parasitemia ${ }^{35}$. Parasitemia analysis was initiated 19 days after infection of mice with $T$. cruzi, according to Brener's technique ${ }^{36}$; this was 4 days after the implementation of environmental enrichment. Parasitemia was evaluated during enrichment treatment only, and the behaviors displayed by mice were grouped for analyses (Figure 1B). Blood $(5 \mu \mathrm{L})$ extracted from each mouse's caudal vein was placed on a microscope slide with a $22 \times 22 \mathrm{~mm}$ glass slide coverslip. Microscope slides were analyzed under a 4,000 -factor microscope at $40 \times$ magnification. The slides were divided into 50 random fields for parasite counts. After counting, the number of parasites was multiplied by the microscope's factor to achieve the true parasitemia value. Parasitemia curves for enriched and non-enriched mice were compared.

\section{Inflammatory mediators}

Plasma samples from mice collected from the orbital venous sinus were also used to assess circulating levels of monocyte chemoattractant protein (CCL2) (Mouse CCL2/JE/MCP-1 DuoSet Elisa Kit, R\&D Systems, MN, USA), IL-10 (Mouse interleukin 10, IL-10 Elisa kit, BioSource, CA, USA), and TNF (Mouse TNF-alpha quantitative Elisa kit, R\&D Systems, MN, USA). All procedures followed manufacturer protocols. Blood samples for cytokine/chemokine analysis were collected from subject mice at 14:00 on the last day of the post-enrichment treatment as a terminal procedure, 148 days after infection by T. cruzi. All samples were measured simultaneously in duplicate.

\section{Statistical analysis}

Behavioral data did not follow a normal distribution according to the Anderson-Darling normality test; thus, nonparametric statistics were used throughout. The Friedman test with Dunn's post-hoc analysis was used to evaluate behavioral differences among the three treatments and the three environmental enrichment items; Bonferroni correction was applied, and thus significant values were achieved at $\alpha=$ 0.02. A Mann-Whitney test was used to evaluate behavioral differences between infected and non-infected mice and between enriched and non-enriched mice (for enriched mice, behavioral data collected for all three environmental enrichment items were pooled and analyzed together). These analyses were run with a confidence level of $95 \%(\alpha=0.05)$ using Minitab 16 and Prisma 5.0 $0^{37}$.

Physiological data were normally distributed, according to the Anderson-Darling normality test; thus, parametric tests were used throughout. One-way ANOVA was used to evaluate differences in inflammatory mediators and heart weight among the experimental groups. An independent sample $t$-test was used to evaluate differences in parasitemia in the experimental groups. Areas under the curve (AUCs) were calculated to determine if numbers of blood parasites differed between enriched and non-enriched mice. The AUC was derived from parasite concentration and time, measuring how long parasites remain in mouse blood. All tests were run with a confidence level of $95 \%(\alpha=0.05)$ using Minitab 16 and Prisma 5.0 $0^{37}$.

\section{RESULTS}

\section{Behavioral data}

Mouse behavior was significantly affected by enrichment treatment. Inactivity was significantly more common in the nonenriched group than in the enriched group, both for infected and non-infected mice (Figure 2 A, B). In addition, both infected and non-infected mice showed an increase in cage exploration during enrichment treatment, but this increase was only significant for the non-infected group (Table 2). Invisibility increased during enrichment treatment in both groups, while roof exploration decreased during enrichment treatment only in the infected group (Table 2).Grooming was less frequent in both the non-infected and infected groups during enrichment treatment (Table 2).

Allogrooming occurred at different rates in the enriched and non-enriched groups. Among enriched mice, it was more commonly performed in the infected group than in the noninfected group, while among non-enriched mice, allogrooming was more common among non-infected than infected mice (Figure 2 C, D). Allogrooming was significantly more common in the non-enriched group, both among infected and noninfected mice (Figure 2 C, D). Negative social interactions were also exhibited significantly more frequently by the non-enriched group, both among infected and non-infected mice (Figure 2 E).

Abnormal behaviors in infected mice did not significantly differ between the enriched and non-enriched groups, although they were recorded more often in the non-enriched group (Figure 2 F). Among non-infected mice, the expression of abnormal behaviors was significantly lower in the enriched group than in the non-enriched group (Figure 2 F). Abnormal behaviors diminished post-enrichment only in the infected group (Table 2).

In comparing the three enrichment treatments, grooming occurred more frequently when the PVC pipe was used for enrichment and less frequently when the egg box was used in both infected and non-infected groups [infected: $F=20.68$, $\mathrm{p}<0.01$; non-infected: $\mathrm{F}=18.00, \mathrm{p}<0.01 ; \mathrm{n}=20$, degrees of freedom $(\mathrm{DF})=2$ for both tests]. Infected mice became more inactive when the straw nest was offered, and non-infected mice became more inactive when the PVC pipe was offered (infected: $\mathrm{F}=19.30, \mathrm{p}<0.01 ;$ non-infected: $\mathrm{F}=21.19, \mathrm{p}<0.01 ; \mathrm{n}=20$, $\mathrm{DF}=2$ for both tests). The category not visible was recorded more frequently when the egg box was offered in both groups (infected: $\mathrm{F}=30.10, \mathrm{p}<0.01$; non-infected: $\mathrm{F}=30.10, \mathrm{p}<0.01$; $\mathrm{n}=20, \mathrm{DF}=2$ for both tests).

\section{Physiological data}

For most days, the parasitemia curves of enriched mice were lower than those of non-enriched mice, but this was only significant on day $33(t$-test $=2.1, \mathrm{p}=0.04, \mathrm{DF}=18)$. The numbers of parasites in the enriched mice were significantly lower than those of the non-enriched mice (AUC enriched: 2,910; AUC non-enriched: 3,089). 


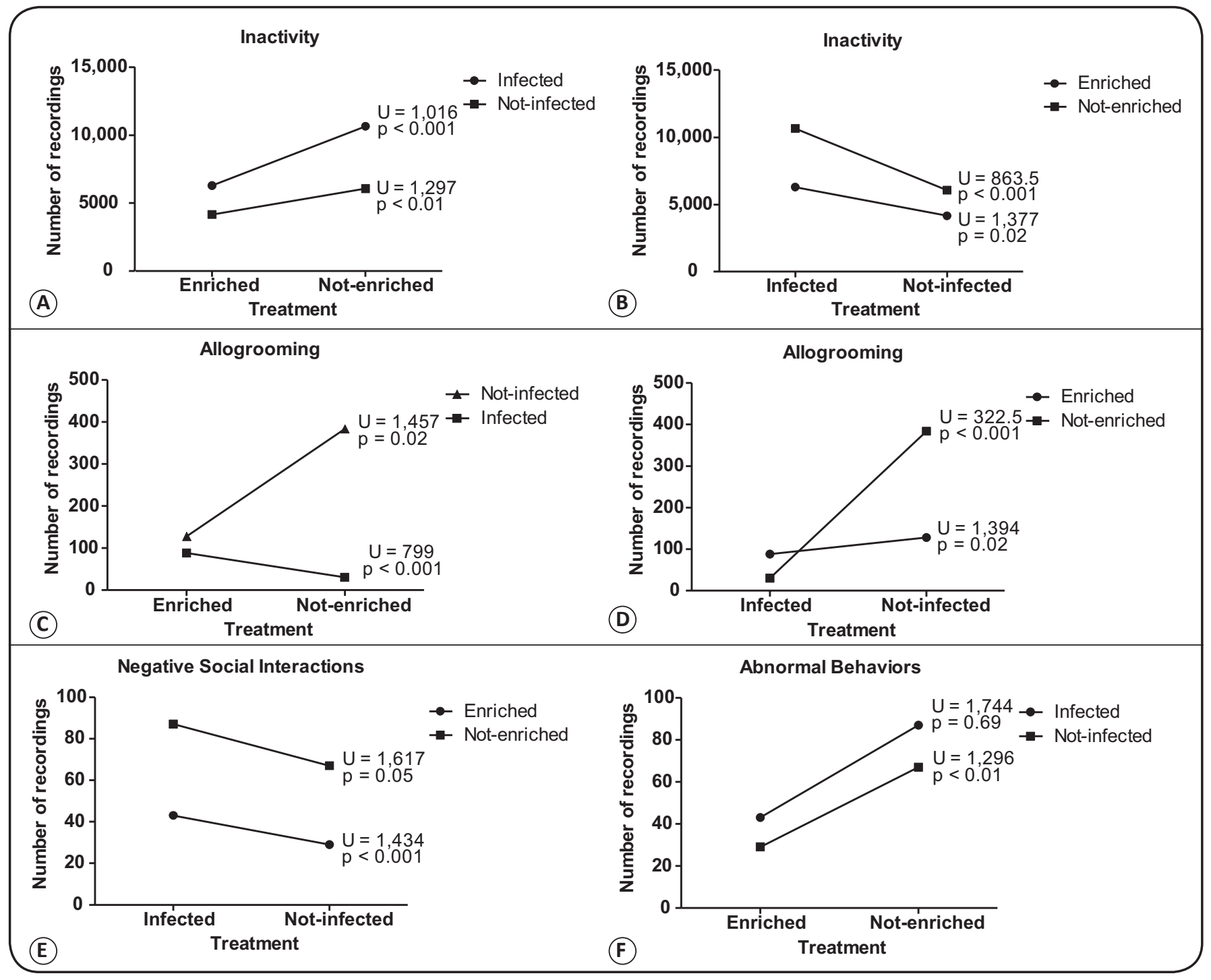

FIGURE 2 - Behavioral comparisons of the effects of Trypanosoma cruzi infection on the enriched and non-enriched groups and between the effects of enrichment on the infected and non-infected groups. $\mathrm{U}$ : Mann-Whitney test, $\mathbf{n}=\mathbf{4 0}, \mathrm{DF}=\mathbf{2}$.

Infected mice produced more TNF than non-infected mice, especially under non-enrichment conditions (Figure 3A). Generally, enriched mice produced less TNF than non-enriched mice in both infected and non-infected groups; however, these differences were not statistically significant (Figure 3A). Environmental enrichment decreased the production of CCL2 both in infected and non-infected mice (Figure 3B). While no significant differences were found among groups in terms of IL-10 production, there was slightly reduced production of this cytokine in the enriched groups (Figure 3C).

Finally, no differences were found in heart weight among the groups $(\mathrm{F}=1.39, \mathrm{p}=0.26, \mathrm{n}=10, \mathrm{DF}=3)$, with an average weight $( \pm \mathbf{S D})$ of $5.2 \times 10^{-3} \pm 2.3 \times 10^{-4}$ in infected and enriched mice, $5.4 \times 10^{-3} \pm 5.4 \times 10^{-4}$ in infected and non-enriched mice, $4.0 \times 10^{-3} \pm 6.2 \times 10^{-4}$ in non-infected and enriched mice, and $4.0 \times 10^{-3} \pm 6.2 \times 10^{-4}$ in non-infected and non-enriched mice.

\section{DISCUSSION}

In this study, we found that environmental enrichment decreased inactivity in both $T$. cruzi-infected and non-infected mice and decreased roof exploration in the infected group. The non-infected group showed an increase in cage exploration and a reduction in grooming. Abnormal behaviors decreased only for the infected group and only in the post-enrichment period. Similar increases in activity and decreases in inactivity have been observed in many studies of environmental enrichment ${ }^{8,38-40}$. With an increase in stimulation inside the cage, mice have more opportunities to explore items, resulting in more activity and less inactivity. Increased activity levels benefit captive animals by helping them avoid boredom, a symptom normally seen in non-enriched environments ${ }^{8}$. However, enriched mice can spend more time interacting with the enrichment items than moving through the cage ${ }^{41}$. Notably, one study showed that mice kept 
TABLE 2

Comparisons between the behaviors expressed by the infected and non-infected C57BL/6 mice during the baseline, enrichment, and post-enrichment treatments (mean \pm standard error).

\begin{tabular}{|c|c|c|c|c|c|}
\hline \multirow{2}{*}{ Behaviors } & \multicolumn{3}{|c|}{ Treatments } & \multirow[b]{2}{*}{ Friedman statistic } & \multirow[b]{2}{*}{$p$-value } \\
\hline & baseline & enrichment & post-enrichment & & \\
\hline GRO EI & $31.08 \pm 1.67$ & $25.13 \pm 2.47$ & $44.13 \pm 3.12$ & 5.70 & 0.06 \\
\hline GRO ENI & $36.10 \pm 2.69^{\mathrm{a}}$ & $19.52 \pm 2.05^{\mathrm{b}}$ & $37.12 \pm 2.61^{\mathrm{a}, \mathrm{c}}$ & 28.46 & $<0.0001^{*}$ \\
\hline EXP EI & $24.77 \pm 2.99$ & $29.50 \pm 4.49$ & $20.78 \pm 3.31$ & 1.32 & 0.52 \\
\hline EXR EI & $14.00 \pm 2.35^{\mathrm{a}}$ & $6.58 \pm 0.51^{\mathrm{b}}$ & $3.93 \pm 0.96^{\mathrm{b}, \mathrm{c}}$ & 22.34 & $<0.0001 *$ \\
\hline EXR ENI & $10.47 \pm 1.18$ & $11.57 \pm 1.66$ & $8.13 \pm 1.38$ & 4.10 & 0.13 \\
\hline IS- EI & $0.08 \pm 0.05$ & $0.13 \pm 0.09$ & $0.00 \pm 0.00$ & 2.00 & 0.37 \\
\hline IS- ENI & $0.02 \pm 0.02$ & $0.75 \pm 0.28$ & $0.07 \pm 0.05$ & 7.82 & $0.02 *$ \\
\hline ABN ENI & $0.52 \pm 0.24$ & $0.43 \pm 0.16$ & $0.40 \pm 0.16$ & 0.1600 & 0.92 \\
\hline NV EI & $8.53 \pm 1.04^{\mathrm{a}}$ & $88.28 \pm 14.30^{\mathrm{a}, \mathrm{b}}$ & $1.97 \pm 0.51^{\mathrm{c}}$ & 59.23 & $<0.0001 *$ \\
\hline NV ENI & $9.10 \pm 1.30^{\mathrm{a}}$ & $79.57 \pm 11.91^{\mathrm{b}}$ & $1.15 \pm 0.49^{\mathrm{c}}$ & 63.17 & $<0.0001 *$ \\
\hline
\end{tabular}

GRO: grooming; EXP: exploration; EXR: roof exploration; IS-: negative social interaction; IN: inactive; ABN: abnormal behaviors; NV: not visible; EI: enriched and infected; ENI: enriched and non-infected. ab,c Different superscript letters indicate statistical differences. *Significant values after Bonferroni correction.
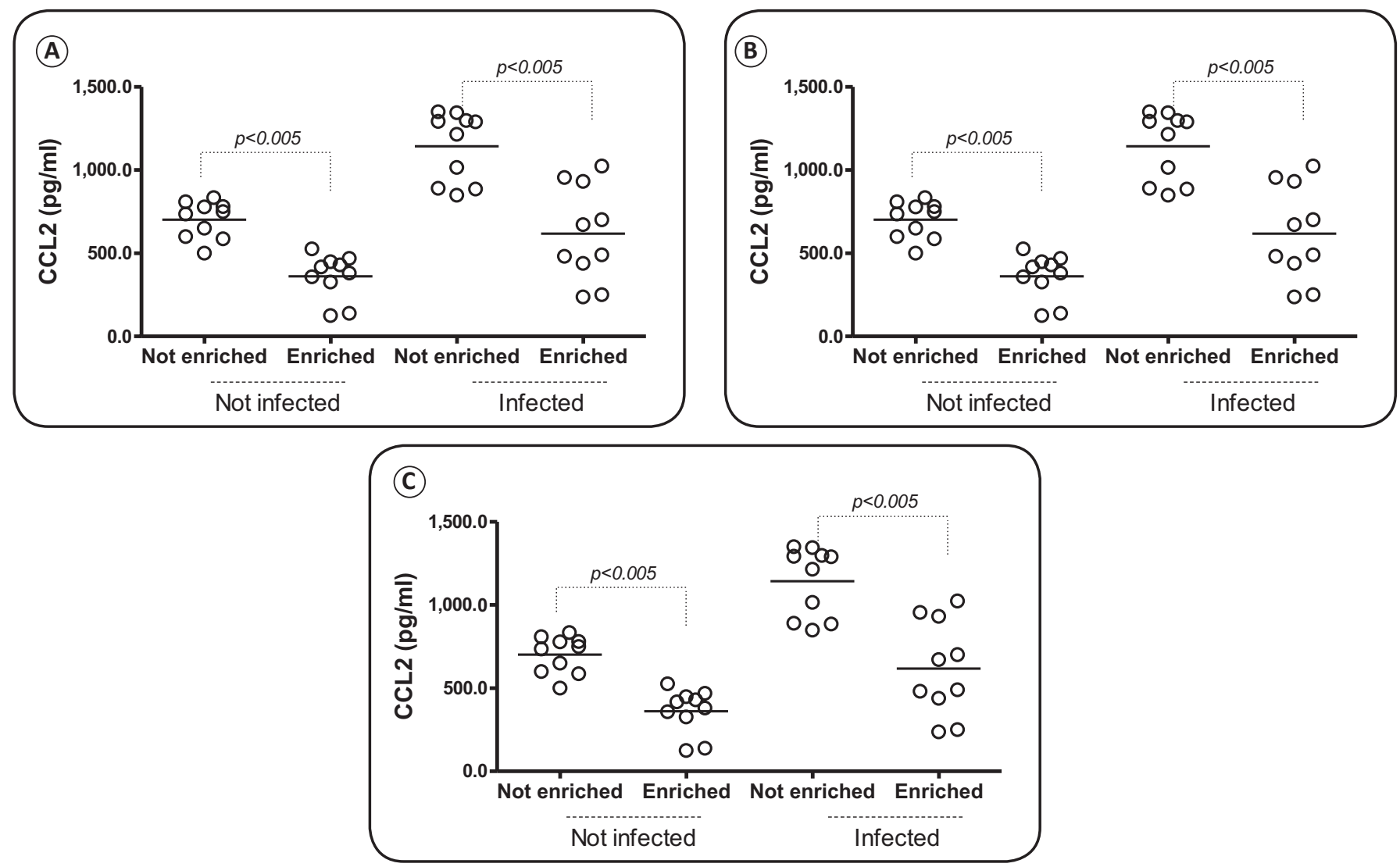

FIGURE 3 - Comparisons of the production of inflammatory mediators in infected and non-infected and enriched and non-enriched groups. (A): TNF (Tumor Necrosis Factor). (B): CCL2 [chemokine (C-C motif) ligand 2]. (C): IL-10 (interleukin-10.) 
in non-enriched cages presented higher activity levels than mice kept in enriched cages ${ }^{42}$. The authors argued that mice explore cages more when no novelty is provided or maintain higher activity levels due to the impossibility of building nests or sleeping or due to increased attempts to escape from the cage. In the present study, when an item was available, mice explored the item more than an empty cage. However, infected mice showed only a slight increase in activity, and this could be a direct reflection of infection with $T$. cruzi, as this parasite increases lethargy in animals ${ }^{43}$.

Environmental enrichment techniques are known to diminish the expression of abnormal behaviors in many animal species $^{8,38,44-47}$. In the present study, abnormal behaviors did not decrease significantly during enrichment treatment in infected groups, showing that the items used may not be adequate for this. A significant reduction in the expression of abnormal behaviors during the post-enrichment period in the infected group, however, showed that the benefits of environmental enrichment can be enduring. For the non-infected groups, environmental enrichment decreased the expression of abnormal behaviors.

Egg boxes elicited more activity from mice than the other enrichment items and could also be used as hiding places. According to the Royal Society for the Prevention of Cruelty to Animals ${ }^{48}$, hiding places are crucial for the maintenance of rodents in laboratories and captivity, increasing their welfare by making them feel safe. The mice in the present study used the egg boxes to hide, reducing the visibility of mice more than the other enrichment items. PVC pipes are cold, poorly ventilated items that are difficult to manipulate, and these characteristics may have induced the mice to avoid them ${ }^{38}$. Straw nests and egg boxes, in contrast, are well-ventilated and more easily manipulated items, permitting all individuals to use them concomitantly, and these characteristics may have been more attractive to animals.

The increase in social interactions in the infected and enriched group suggests a positive influence of environmental enrichment in decreasing the depressive profile generated by the parasite $T$. cruzi $i^{11,49}$. The non-enriched non-infected group exhibited higher levels of allogrooming, corroborating the results of a study ${ }^{42}$ in which mice kept in conventional environments expressed more allogrooming behaviors than mice kept in enriched environments. Similarly, we found that overall, infected mice exhibited less allogrooming than noninfected mice. A further reduction in allogrooming in infected and enriched mice was due to the use of the enrichment items by the animals.

Negative social interactions were recorded significantly less frequently in infected mice than in non-infected mice. Infected animals were less aggressive to other individuals, and this was probably due to their depressive profiles ${ }^{11}$. These animals initiated negative social interactions but soon gave up the confrontations, remaining immobile and inactive, which was also previously reported ${ }^{43}$. Some studies showed that enriched CFLP mice exhibited more aggressive behaviors than nonenriched mice and concluded that environmental enrichment may exacerbate welfare problems ${ }^{50,51,52}$. However, since the expression of negative social interactions did not increase during enrichment treatment in our study, we conclude that the use of enriched environments does not increase stress or aggression ${ }^{49}$.

Trypanosoma cruzi infection alters the immune system of the host, increasing the concentrations of the cytokine TNF and chemokine CCL2 $2^{53,54}$. While environmental enrichment significantly decreased the production of CCL2, TNF concentrations were not significantly altered, although they did decrease in the enriched groups; both are inflammatory mediators that recruit and activate cells to the inflammatory site $^{20}$. IL-10 did not decrease with enrichment, which was expected since expression of this cytokine normally changes only when it is necessary to regulate the inflammatory response $^{21}$. The regulatory cytokine IL-10 acts mainly to control the parasite in the acute phase of infection, inhibiting the action of TNF, which intensifies the inflammatory process ${ }^{55}$. Thus, it is assumed that the presence of TNF at the beginning stage of infection is essential for controlling parasite infection, but its intensification and persistence during longer periods of infection would prejudice the host due to the intensification of the tecidual inflammatory response and consequent functional organ sequel ${ }^{56}$. By decreasing the TNF concentration, environmental enrichment enhanced the immune responses of the mice ${ }^{56}$.

The chemokine CCL2 promotes the attraction of inflammatory cells to inflammatory sites, and together with TNF, it is responsible for the myocarditis induced by parasitism ${ }^{17}$. However, in this study, environmental enrichment did not alter TNF production in infected animals. In contrast, via an unknown pathway, the chemokine CCL2 was reduced in infected mice under environmental enrichment. This pattern is, at least, a precondition for reducing the inflammation in tissues.

The parasitic loads of the enriched mice were also lower than those in the non-enriched mice, showing that environmental enrichment allowed animals to better cope with the parasites by increasing their welfare. Mice infected with Babesia microti and exposed to environmental enrichment took longer to reach a peak of parasitemia, probably due to changes in behavioral, hormonal, and immunocompetence parameters ${ }^{49}$. Environmental enrichment, in this case, promoted more resistance to the parasite. Similar results were found for turkeys (Meleagris gallopavo) ${ }^{58}$. The authors found a detrimental effect of environmental enrichment offered during the first two weeks of life in turkeys, showing that they become more susceptible to bacterial infections later in life. In contrast, two studies found beneficial effects of environmental enrichment on mice infected with encephalitis and influenza virus ${ }^{57,59}$. Finally, environmental enrichment does not compromise the immune response in mice chronically infected with Mycobacterium avium ${ }^{60}$. These studies highlight the importance of evaluating different physiological and behavioral parameters to better understand the effects of environmental enrichment on animals infected with parasites.

In conclusion, environmental enrichment improved the behavioral profile of $T$. cruzi-infected mice, reducing inactivity and increasing cage exploration. Although the expression 
of abnormal behaviors decreased in the infected group during enrichment treatment, the items used were unable to stimulate mice to eliminate or significantly reduce these behaviors. Environmental enrichment also improved the physiological profile of T. cruziinfected mice, reducing the production of some inflammatory mediators and parasitemia. Thus, enriched mice should be used preferentially in parasitological studies, as it enhances the quality of the results. This should facilitate the development of better treatments for diseases, consequently benefitting public health.

\section{Acknowledgements}

The authors would like to thank R.J.Y. for invaluable suggestions on the first draft of this paper. Special thanks to the Laboratory of Vertebrate Zoology/ Departamento de Biodiversidade, Evolução e Meio Ambiente, Fundação de Amparo à Pesquisa de Minas Gerais, Conselho Nacional de Desenvolvimento Cientifico e Tecnológico, and the Federal University of Ouro Preto. A.T. is also supported by a fellowship for research productivity from Conselho Nacional de Desenvolvimento Científico e Tecnológico.

\section{Financial Support}

There is no financial support to acknowledge for this study.

\section{Conflict of interest}

The authors declare that have no conflicts of interest.

\section{REFERENCES}

1. Comitee on Recognition and Alleviation of Distress in Laboratory Animals. Recognition and Alleviation of Distress in Laboratory Animals. Washington: The National Academies Press; 2008. 132p.

2. Mason G, Rushen J. Stereotypic animal behaviour: fundamentals and applications to welfare. Wallingford: CABI; 2006. 367p.

3. Gröer M, Meagher MW, Kendall-Tackett K. An overview of stress and immunity. In: Kendall-Tackett KA, editor. The psychoneuroimmunology of chronic disease: exploring the links between inflammation, stress, and illness. Whasington: American Psychological Association; 2009. p. 9-22.

4. Pinheiro AA, Brito IF. Bem-estar e produção animal. Sobral: Embrapa Caprinos; 2009. 27p.

5. Bayne K, Wurbel H. The impact of environmental enrichment on the outcome variability and scientific validity of laboratory animal studies. Rev Sci Tech Off Int Epiz. 2014;33(1):273-80.

6. Bayne K. Potential for unintended consequences of environmental enrichment for laboratory animals and research results. ILAR J. 2005;46(2):129-39.

7. Coleman K, Weed JL, Schapiro SJ. Environmental enrichment for animals used in research. In: Conn PM, editor. Animal models for the study of human disease. London: Academic Press; 2013. p. 75-94.

8. Young RJ. Environmental enrichment for captive animals. Oxford: Blackwell Science; 2003. 240p.

9. Shepherdson DJ, Mellen JD, Hutchins M. Second nature: environmental enrichment for captive animals. Washington: Smithsonian Institution Press; 1998. 376p.

10. Reinhardt V, Reinhardt A. Variables, refinement and environmental enrichment for rodents and rabbits kept in research institutions: making life easier for animals in laboratories. Washington: Animal Welfare Institute; 2006. 71p.
11. Silva AA, Pereira GV, Souza AS, Silva RR, Rocha MS, LannesVieira J. Trypanosoma cruzi-induced central nervous system alterations: from the entry of inflammatory cells to potential cognitive and psychiatric abnormalities. J Neuroparasit. 2010; 1:1-13.

12. Pizzutto CS, Sgai MGFG, Lopes DA, Pessutti C, Nunes A, Furtado $\mathrm{PV}$, et al. Relation between the level of self-mutilation and the concentration of fecal metabolites of glucocorticoids in captive chimpanzees (Pan troglodytes). Pesq Vet Bras. 2015;35(1):62-6.

13. Morgan KN, Tromborg CT. Sources of stress in captivity. Appl Anim Behav Sci. 2007;102:262-302.

14. Mason GJ. Species differences in responses to captivity: stress, welfare and the comparative method. Trends Ecol Evol. 2010;25(12):712-21.

15. Martin LB, Kidd L, Liebl AL, Coon CAC. Captivity induces hyperinflammation in the house sparrow (Passer domesticus). J Exp Biol 2011;214(Pt 15):2579-85.

16. Chagas C. Nova tripanozomiase humana: estudos sobre a morfologia e o ciclo evolutivo do Schizotrypanum cruzi n. gen., n. sp., agente etiológico de nova entidade mórbida do homem. Mem Inst Oswaldo Cruz. 1909;1:159-218.

17. Talvani A, Rocha MOC, Barcelos LS, Gomes YM, Ribeiro AL, Teixeira MM. Elevated concentrations of CCL2 and tumor necrosis fator-alpha in chagasic cardiomyopathy. Clin Infec Dis. 2004;38(7):943-50.

18. Arantes JM, Francisco AF, de Abreu Vieira PM, Silva M, Araujo MSS, de Carvalho AT, et al. Trypanosoma cruzi: desferrioxamine decreases mortality and parasitemia in infected mice through a trypanostatic effect. Exp Parasitol. 2011;128(4):401-8.

19. Engman DM, Leon JS. Pathogenesis of Chagas heart disease: role of autoimmunity. Acta Trop. 2002;81(2):123-32.

20. Talvani A, Ribeiro CS, Alberti JC, Michailowsky V, Santos PV, Murta SM, et. al. Kinetics of cytokine gene expression in experimental chagasic cardiomyopathy: tissue parasitism and endogenous IFN-gamma as important determinants of chemokine mRNA expression during infection with Trypanosoma cruzi. Microbes Infect. 2000;2(8):851-66.

21. Talvani A, Teixeira MM. Inflammation and Chagas disease: some mechanisms and relevance. Adv Parasitol. 2011;76:171-94.

22. Hunter CA, Ellis-Neyes LA, Slifer T, Kanaly S, Grunig G, Fort M, et. al. IL-10 is required to prevent immune hyperactivity during infection with Trypanosoma cruzi. J Immunol. 1997;158(7):3311-16.

23. Golgher D, Gazzinelli RT. Innate and acquired immunity in the pathogenesis of Chagas disease. Autoimmunity. 2004;37(5): 399-409.

24. Moser B, Loetscher P. Lymphocyte traffic control by chemokines. Nat Immunol. 2001;2(2):123-8.

25. Machado FS, Koyama NS, Carregaro V, Ferreira VR, Milanezi CM, Teixeira MM, et. al. CCR5 plays a critical role in the development of myocarditis and host protection in mice infected with Trypanosoma cruzi. J Infect Dis. 2005; 191(4):627-36.

26. Hardison JL, Wrightsman RA, Carpenter PM, Lane TE, Manning JE. The chemokines CXCL9 and CXCL10 promote a protective immune response but do not contribute to cardiac inflammation following infection with Trypanosoma cruzi. Infect Immun. 2006;74(1):125-34.

27. D'Avila DA, Guedes PMM, Castro AM, Gontijo ED, Chiari E, Galvão LM. Immunological imbalance between IFN-gamma and IL-10 levels in the sera of patients with the cardiac form of Chagas disease. Mem Inst Oswaldo Cruz. 2009;104(1):100-5. 
28. Esper L, Talvani A, Pimentel P, Teixeira MM, Machado FS. Molecular mechanisms of myocarditis caused by Trypanosoma cruzi. Curr Opin Infect Dis. 2015;28(3):246-52.

29. Müller GCK, Greinert JA, Silva-Filho HH. Frequência de parasitas intestinais em felinos mantidos em zoológicos. Arq Bras Med Vet Zootec. 2005;57(4):559-61.

30. Zingales B, Andrade SG, Briones MRS, Campbell DA, Chiari E, Fernandes O, et al. A new consensus for Trypanosoma cruzi intraspecific nomenclature: second revision meeting recommends TcI to TcVI. Mem Inst Oswaldo Cruz. 2009;104(7):1051-4.

31. Silva RR, Shrestha-Bajracharya D, Almeida-Leite CM, Leite R, Bahia MT, Talvani A. Short-term therapy with simvastatin reduces inflammatory mediators and heart inflammation during the acute phase of experimental Chagas disease. Mem Inst Oswaldo Cruz. 2012;107(4):513-21.

32. Conselho Nacional de Controle e Experimentação Animal (CONCEA). Diretrizes de prática de eutanásia do CONCEA. Brasília: Diretriz; 2013. 24p.

33. Martin P, Bateson P. Measuring Behaviour: an introductory guide. $2^{\text {nd }}$ ed. Cambridge: Cambridge University Press; 2007. 186p.

34. Olsson IAS, Sherwin CM. Behaviour of laboratory mice in different housing conditions when allowed to self-administer an anxiolytic. Lab Anim 2006;40(4):392-9.

35. Penitente AR, Leite AL, Costa GP, Shrestha D, Horta AL, Natali AJ, et. al. Enalapril in Combination with Benznidazole Reduces Cardiac Inflammation and Creatine Kinases in Mice Chronically Infected with Trypanosoma cruzi. Am J Trop Med Hyq. 2015;93(5):976-82.

36. Brener Z. Therapeutic activity and criterion of cure on mice experimentally infected with Trypanosoma cruzi. Rev Inst Med Trop São Paulo. 1962;4:389-96.

37. Zar JH. Biostatistical Analysis. $5^{\text {th }}$ ed. New Jersey: Prentice Hall; 2009. 960p.

38. Brice BD, Stephens MR, Georges SJ, Venancio AR, Bermont PC, Warncke AV, et al. Environmental enrichment induces pericyte and IgA-dependent wound repair and lifespan extension in a colon tumor model. Cell Rep. 2017;19(4):760-73.

39. Würbel H. Environmental enrichment does not disrupt stardardization of animal experiments. Altex. 2007;24 (spe issue):70-3.

40. Andrade AA, Azevedo CS. Efeitos do enriquecimento ambiental na diminuição de comportamentos anormais exibidos por papagaiosverdadeiros (Amazona aestiva, Psittacidae) cativos. Rev Bras Ornitol. 2011;19(1):56-62.

41. Van de Weerd HA, Aarsen EL, Mulder A, Kruitwagen CL, Hendriksen CF, Baumans V. Effects of environmental enrichment for mice: variation in experimental results. Appl Anim Behav Sci. 2002;5(2):87-109.

42. Marques JM, Olsson IAS. The effect of preweaning and postweaning housing on the behaviour of the laboratory mouse (Mus musculus). Lab Anim. 2007;41(1):92-102.

43. Pereira GV, Silva AA, Pereira IR, Silva RR, Moreira OC, de Almeida LR, et. al. Trypanosoma cruzi-induced depressive like behaviour is independent of meningoencephalitis but responsive to parasiticide and TNF-targeted therapeutic interventions. Brain Behav Immun. 2012;26(7):1136-49.

44. Ceballos MC, Góis KCR, Carvalhal MVL, Costa FO, Costa MP. Environmental enrichment for rabbits reared in cages reduces abnormal behaviors and inactivity. Cienc Rural 2016;46(6):1088-93.
45. Swaisgood RR, Shepherdson DJ. Scientific approaches to enrichment and stereotypies in zoo animals: what's been done and where should we go next? Zoo Biol. 2005;24(6):499-518.

46. Bechard A, Meagher R, Mason G. Environmental enrichment reduces the likelihood of alopecia in adult C57BL/6J mice. J Am Assoc Lab Anim Sci. 2011;50(2):171-4.

47. Azevedo CS, Lima MFF, Cipreste CF, Young RJ, Rodrigues M. Using environmental enrichment to reduce the expression of abnormal behaviours in greater rhea Rhea americana at Belo Horizonte Zoo. Int Zoo Yearb. 2013;47(1):163-70.

48. Royal Society for the Prevention of Cruelty to Animals (RSPCA). Recursos suplementares para membros de processos locais de revisão ética: camundongos. West Sussex: RPCA; 2008. 8p.

49. Vilar-Pereira G, Silva AA, Pereira IR, Silva RR, Moreira OC, Almeida LR, et al. Trypanosoma cruzi-induced depressive-like behaviour is independent of meningocephalitis but responsive to parasiticide and TNF-targeted therapeutic interventions. Brain Behav Immun. 2012;26(7):1136-49.

50. Abou-Ismail UA. The effects of cage enrichment on agonistic behaviour and dominance in male laboratory rats (Rattus norvegicus). Res Vet Sci. 2011;90(2):346-51.

51. Van de Weerd HA, Aarsen EL, Mulder A, Kruitwagen CL, Hendriksen CF, Baumans V. Effects of environmental enrichment for mice: variation in experimental results. Appl Anim Behav Sci. 2002;5(2):87-109.

52. Toth LA, Kregel K, Lean L, Musch TI. Environmental enrichment of laboratory rodents: the answer depends on the question. Comparative Med. 2011;61(4):314-21.

53. Machado FS, Martins GA, Aliberti JCS, Mestriner FL, Cunha FQ, Silva JS. Trypanosoma cruzi-infected cardiomyocytes produce chemokines and cytokines that trigger potente nitric oxidedependent trypanocidal activity. Circulation 2000;102:3003-8.

54. Teixeira MM, Gazzinelli RT, Silva JS. Chemokines, inflammation and Trypanosoma cruzi infection. Trends Parasitol. 2002;18(6): 262-65.

55. Moore KW, Malefyt RW, Robert L, O'Garra A. Interleukin-10 and the interleukin-10 receptor. Annu Rev Immun. 2001;19:683-765.

56. Kroll-Palhares K, Silvério JC, Silva AA, Michailowsky V, Marino AP, Silva NM, et. al. TNF/TNFR1 signaling up-regulates CCR5 expression by $\mathrm{CD} 8+$ lymphocytes and promotes heart tissue damage during Trypanosoma cruzi infection: beneficial effects of TNF- $\alpha$ blockade. Mem Inst Oswaldo Cruz. 2008;103(4):375-85.

57. Jurgens HA, Johnson RW. Environmental enrichment attenuates hippocampal neuroinflammation and improves cognitive function during influenza infection. Brain Behav Immun. 2012;26(6): 1006-16.

58. Huff GR, Huff WE, Balog JM, Rath NC. The effects of behaviour and environmental enrichment on disease resistance of turkeys. Brain Behav Immun. 2003;17:339-49.

59. Sousa AA, Reis R, Bento-Torres J, Trévia N, Lins NA, Passos $A$, et. al. Influence of enriched environment on viral encephalitis outcomes: behavioral and neuropathological changes in albino swiss mice. Plos One. 2011;6(1):e15597.

60. Olsson IAS, Costa A, Nobrega C, Roque S, Correia-Neves M. Environmental enrichment does not compromise the immune response in mice chronically infected with Mycobacterium avium. Scand J Immunol. 2010;71(4):249-57. 